\title{
Physical and oxidative stability of n-3 delivery emulsions added seaweed-based polysaccharide extracts from Nordic brown algae Saccharina latissima
}

\author{
Ditte Hermund ${ }^{1}$, Ioanna Anagnostara ${ }^{1}$, Xiaoru $\mathrm{Hou}^{2}$, Maria Mikkelsen ${ }^{3}$, Nanna \\ Rhein-Knudsen ${ }^{3}$, Anne-Belinda Bjerre ${ }^{2}$, Anne Meyer ${ }^{3}$, and Charlotte Jacobsen ${ }^{1}$ \\ ${ }^{1}$ DTU Fødevareinstituttet \\ ${ }^{2}$ Danish Technological Institute \\ ${ }^{3}$ DTU Bioengineering
}

October 1, 2021

\begin{abstract}
Enriching foods with long-chain (LC) n-3 polyunsaturated fatty acids (PUFAs) requires a delivery emulsion system, which is both thermodynamically and oxidatively stable. The antioxidant and stabilizing properties of three types of polysaccharide extracts from brown algae Saccharina latissima with mixed composition of polysaccharides (SA: 98\% Sodium alginate, SF: $90 \%$ alginate and 9\% fucoidan, SL: 14.5\% fucoidan, 9.5\% laminarin and co-extracted non-polysaccharides) were evaluated. SA, SF, SL and REF (added commercial sodium alginate) all showed in vitro ferrous ion chelating ability in the order: $\mathrm{SA}(99 \%)>\mathrm{SL}(78 \%)>\operatorname{REF}(31 \%)>\mathrm{SF}(16 \%)$. The difference in antioxidant activity between SA, REF and SF appeared related to structural differences of alginate $(\mathrm{M} / \mathrm{G}$ ratio). A storage trial was conducted using $70 \%(\mathrm{w} / \mathrm{w})$ fish oil-in-water delivery emulsions added sodium caseinate (NaCas) $(0.23 \mathrm{wt} \%$ ) as emulsifier in combination with SA, SF, SL or commercial NaAlg (REF) in different concentrations $(\mathrm{C} 1=0.1, \mathrm{C} 2=0.2 \mathrm{C} 3=0.3$ and $\mathrm{C} 4=0.4 \mathrm{wt} \%)$. A control with only NaCas were included $(\mathrm{CON})$. The physical (e.g. creaming and droplet-size distribution) and oxidative (peroxide value and volatiles) stability of the emulsions, were evaluated (12 days, dark at 20@C). Acceptable physical stability (creaming index, CI) was found for, REF (all concentrations), $\mathrm{SF}=0.2 \mathrm{wt} \%(\mathrm{C} 2), \mathrm{SL}$ and $\mathrm{SA}=0.3 \mathrm{wt} \%(\mathrm{C} 3)$ and $0.4 \mathrm{wt} \%$ (C4). In general, the oxidative stability decreased by adding REF, SA and SF (except for REF at C1), as prooxidant activity was observed. However, SA showed antioxidant activity against formation of 2-ethylfuran. SL showed antioxidant activity in decreasing formation of volatile compounds in emulsions when added in concentrations above $0.2 \mathrm{wt} \%$.
\end{abstract}

\section{Hosted file}

JAOCS_Manuscript_sept2021.docx available at https://authorea.com/users/438814/articles/ 539931-physical-and-oxidative-stability-of-n-3-delivery-emulsions-added-seaweed-basedpolysaccharide-extracts-from-nordic-brown-algae-saccharina-latissima 

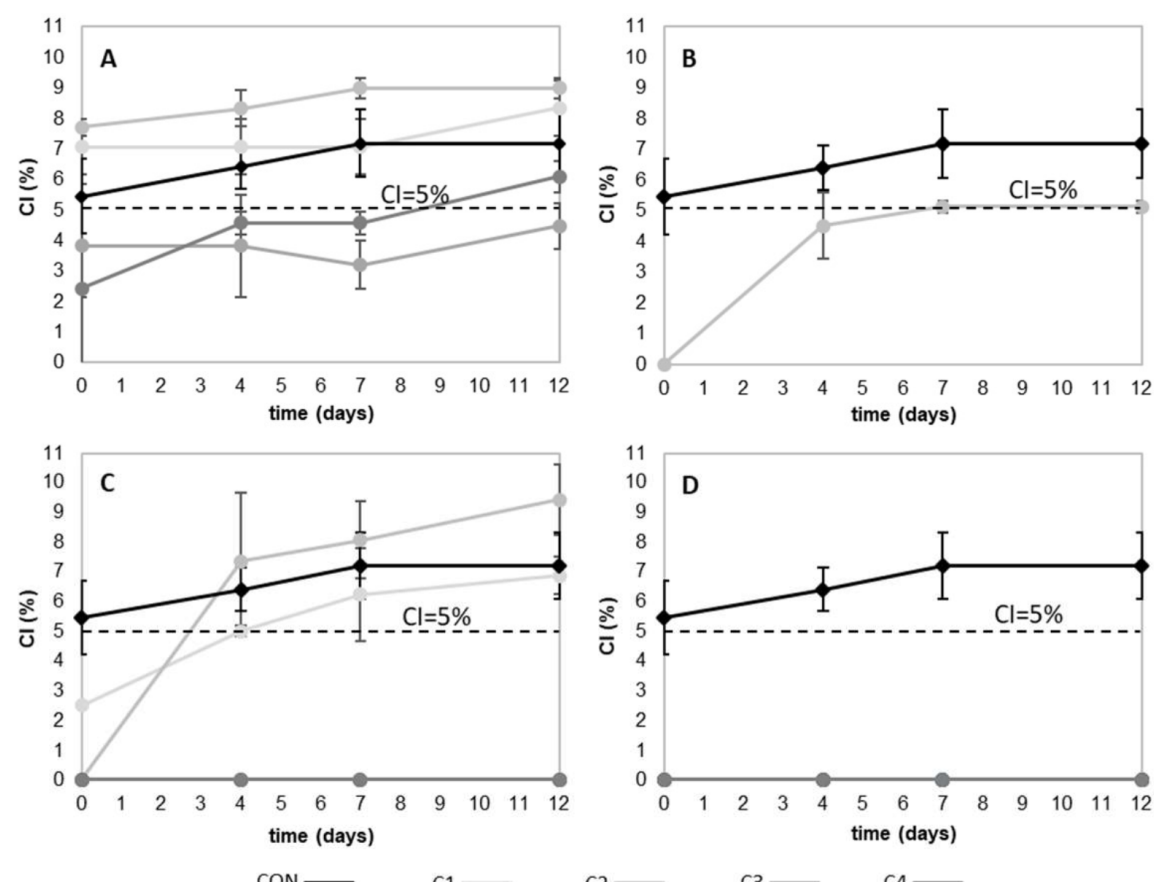

$\mathrm{C} 2-\mathrm{C} 3-\mathrm{C} 4-$
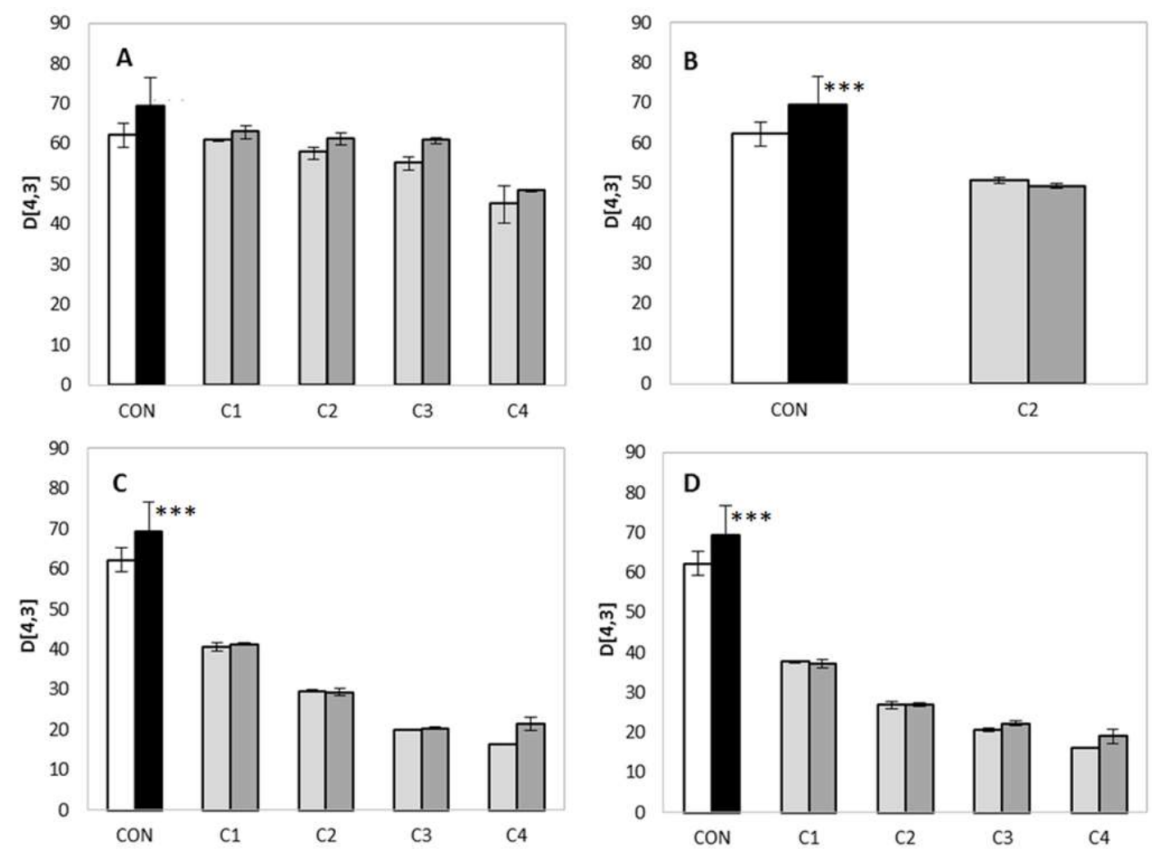


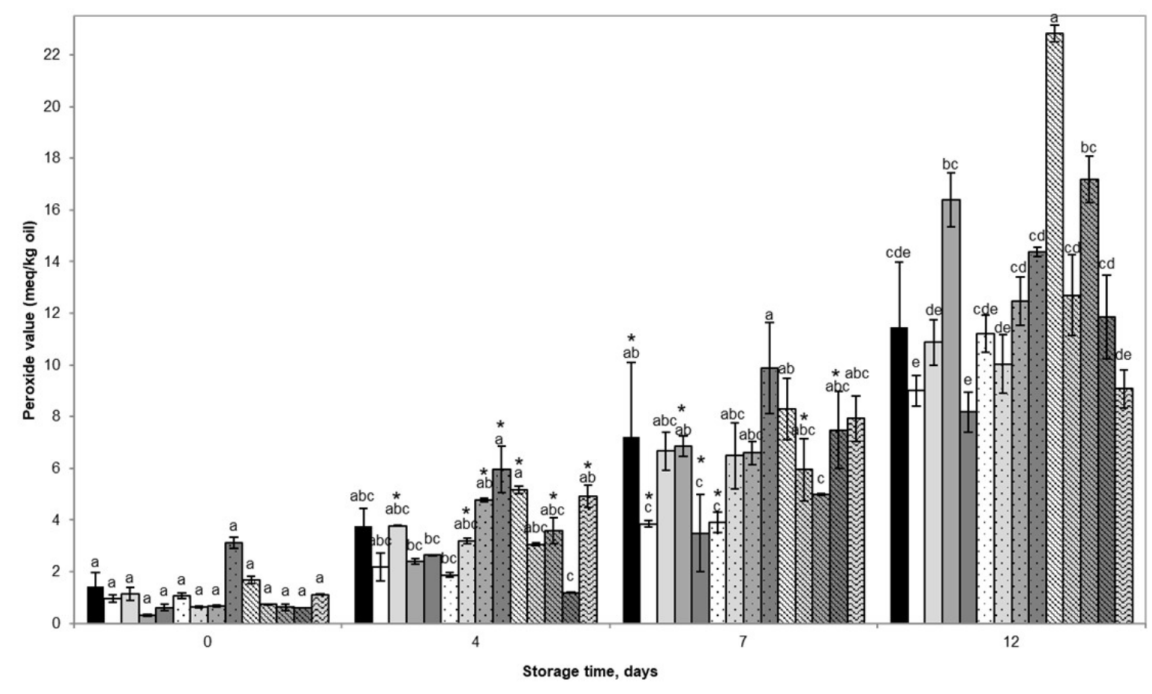

-CON aSL_C1 aSL_C2 aSL_C3 aSL_C4 aSA_C1 aSA_C2 aSA_C3 aSA_C4 aREF_C1 घREF_C2 aREF_C3 घREF_C4 ఐSF_C2
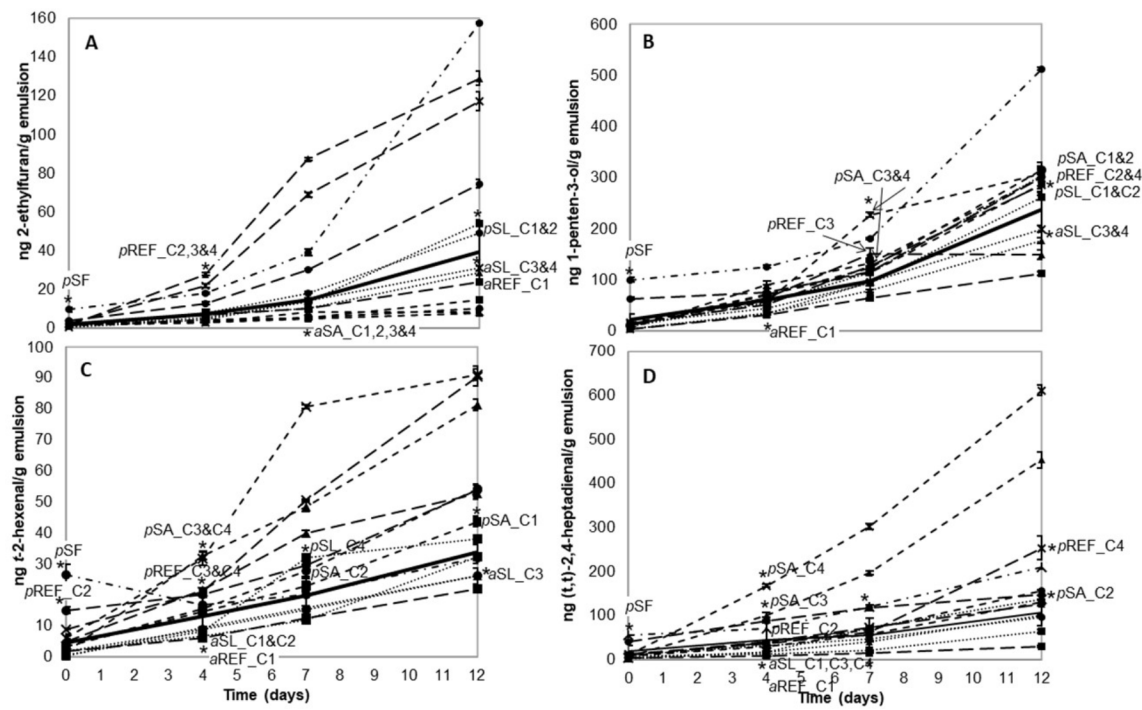

\section{Hosted file}

Table 1.docx available at https://authorea.com/users/438814/articles/539931-physicaland-oxidative-stability-of-n-3-delivery-emulsions-added-seaweed-based-polysaccharideextracts-from-nordic-brown-algae-saccharina-latissima

\section{Hosted file}

Table 2.docx available at https://authorea.com/users/438814/articles/539931-physicaland-oxidative-stability-of-n-3-delivery-emulsions-added-seaweed-based-polysaccharideextracts-from-nordic-brown-algae-saccharina-latissima 